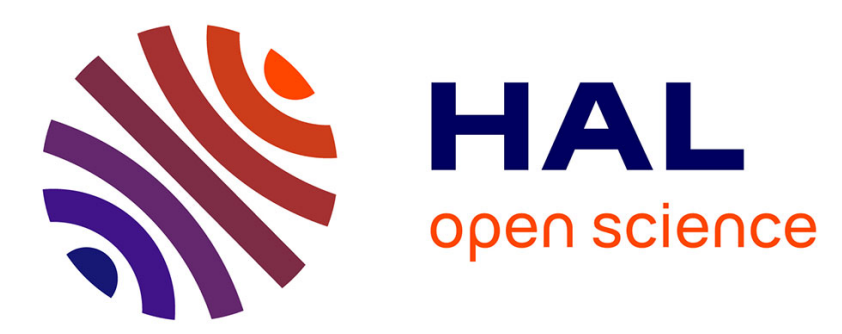

\title{
Low temperature Mössbauer study and magnetic susceptibility measurements on YbMo6S8 and TmMo6S8
}

P. Bonville, J.A. Hodges, P. Imbert, G. Jehanno, R. Chevrel, M. Sergent

\section{- To cite this version:}

P. Bonville, J.A. Hodges, P. Imbert, G. Jehanno, R. Chevrel, et al.. Low temperature Mössbauer study and magnetic susceptibility measurements on YbMo6S8 and TmMo6S8. Revue de Physique Appliquée, 1980, 15 (6), pp.1139-1142. 10.1051/rphysap:019800015060113900 . jpa-00244832

\section{HAL Id: jpa-00244832 https://hal.science/jpa-00244832}

Submitted on 1 Jan 1980

HAL is a multi-disciplinary open access archive for the deposit and dissemination of scientific research documents, whether they are published or not. The documents may come from teaching and research institutions in France or abroad, or from public or private research centers.
L'archive ouverte pluridisciplinaire HAL, est destinée au dépôt et à la diffusion de documents scientifiques de niveau recherche, publiés ou non, émanant des établissements d'enseignement et de recherche français ou étrangers, des laboratoires publics ou privés. 


\title{
Low temperature Mössbauer study and magnetic susceptibility measurements on $\mathbf{Y b M o}_{6} \mathrm{~S}_{8}$ and $\mathrm{TmMo}_{6} \mathrm{~S}_{8}$
}

\author{
P. Bonville, J. A. Hodges, P. Imbert, G. Jehanno, R. Chevrel (*) and M. Sergent (*) \\ DPh-G/PSRM, CEN Saclay, Boîte Postale no 2, 91190 Gif-sur-Yvette, France
}

(Reçu le 19 novembre 1979, accepté le 14 décembre 1979)

\begin{abstract}
Résumé. - L'étude par effet Mössbauer sur $\mathrm{Yb}^{170}$ et les mesures de susceptibilité magnétique ont montré que $\mathrm{YbMo}_{6} \mathrm{~S}_{8}$ contient en proportions sensiblement équivalentes des ions $\mathrm{Yb}^{2+}$ et $\mathrm{Yb}^{3+}$. Les ions $\mathrm{Yb}^{2+}$ sont soumis à un très fort gradient de champ électrique axial et se meuvent préférentiellement dans le plan perpendiculaire à l'axe de ce gradient (vraisemblablement l'axe hexagonal c). Les moments magnétiques des ions $\mathrm{Yb}^{3+} \mathrm{s}^{\text {'ordonnent }}$ perpendiculairement à l'axe c au-dessous de $T_{\mathrm{N}}=2,75 \mathrm{~K}$ et valent $1,7 \mu_{\mathrm{B}}$ près de zéro Kelvin. Les impuretés d'ytterbium apparaissent également sous les formes $\mathrm{Yb}^{2+}$ et $\mathrm{Yb}^{3+}$ dans $\mathrm{TmMo}_{6} \mathrm{~S}_{8}$, où les ions $\mathrm{Yb}^{3+}$ présentent un tenseur $g$ légèrement anisotrope $\left(g_{\|}=2,32, g_{\perp}=3,64\right)$. Des mesures par effet Mössbauer sur $\operatorname{Tm}^{169}$ montrent la présence d'un seul site de Tm.
\end{abstract}

\begin{abstract}
Mössbauer study on $\mathrm{Yb}^{170}$ and magnetic susceptibility measurements show that $\mathrm{YbMo}_{6} \mathrm{~S}_{8}$ contains both $\mathrm{Yb}^{2+}$ and $\mathrm{Yb}^{3+}$ ions with nearly equal proportions. The $\mathrm{Yb}^{2+}$ ions are submitted to a very strong electric field gradient with axial symmetry and move preferentially in the plane perpendicular to the gradient axis (which is probably the hexagonal axis $\mathrm{c}$ ). The $\mathrm{Yb}^{3+}$ magnetic moments order perpendicularly to the $\mathrm{c}$ axis below $T_{\mathrm{N}}=2.75 \mathrm{~K}$ and their magnitude is $1.7 \mu_{\mathrm{B}}$ near zero Kelvin. Ytterbium impurities also appear as $\mathrm{Yb}^{2+}$ and $\mathrm{Yb}^{3+}$ ions in $\mathrm{TmMo}_{6} \mathrm{~S}_{8}$, where the $\mathrm{Yb}^{3+}$ g-tensor is slightly anisotropic $\left(g_{\|}=2.32, g_{\perp}=3.64\right)$. $\mathrm{Tm}^{169}$ Mössbauer measurements on $\mathrm{TmMo}_{6} \mathrm{~S}_{8}$ show that only one $\mathrm{Tm}$ site is present.
\end{abstract}

The superconducting ternary compounds $\mathrm{RMo}_{6} \mathrm{X}_{8}$, where $\mathrm{R}$ is a metal $(\mathrm{Sn}, \mathrm{Pb}$, Rare Earth,...) and $\mathrm{X}$ represents $\mathrm{S}$ or $\mathrm{Se}$, have been intensively studied during past years, from the point of view of their superconducting as well as their magnetic properties (see [1] for a review).

In this paper we report on the results of a low-temperature study of $\mathrm{YbMo}_{6} \mathrm{~S}_{8}$ and of $\mathrm{Yb}$ impurities diluted in $\mathrm{TmMo}_{6} \mathrm{~S}_{8}$, using the Mössbauer effect on $\mathrm{Yb}^{170}\left(I_{\mathrm{g}}=0, I_{\mathrm{e}}=2\right)$.

We also report on the preliminary results of the study of $\mathrm{TmMo}_{6} \mathrm{~S}_{8}$ using the Mössbauer effect on $\operatorname{Tm}^{169}\left(I_{\mathrm{g}}=\frac{1}{2}, I_{\mathrm{e}}=\frac{3}{2}\right)$.

Finally, we have measured the thermal variation of the powder magnetic susceptibility of $\mathrm{YbMo}_{6} \mathrm{~S}_{8}$ between $4.2 \mathrm{~K}$ and $50 \mathrm{~K}$.

The compounds $\mathrm{YbMo}_{6} \mathrm{~S}_{8}$ and $\mathrm{TmMo}_{6} \mathrm{~S}_{8}$ have the same crystallographic structures (space group : $R \overline{3})$ [2] and the local symmetry at the rare-earth site

(*) Laboratoire de Chimie Minérale B, Faculté des Sciences, avenue du Général Leclerc, 35000 Rennes, France. is trigonal. The ternary axis is the $\mathbf{c}$ axis of the hexagonal cell.

The critical superconducting temperatures are : $T_{\mathrm{c}} \simeq 8.5 \mathrm{~K}$ for $\mathrm{YbMo}_{6} \mathrm{~S}_{8}$ and $T_{\mathrm{c}} \simeq 2 \mathrm{~K}$ for $\mathrm{TmMo}_{6} \mathrm{~S}_{8}$ [2].

Susceptibility measurements on $\mathrm{YbMo}_{6} \mathrm{~S}_{8}$ suggested the existence of a mixture of $\mathrm{Yb}^{2+}$ and $\mathrm{Yb}^{3+}$ ions [2]; furthermore, specific heat measurements in this compound showed a peak at about $2.7 \mathrm{~K}$, which was interpreted as being due to the appearance of antiferromagnetic ordering [3].

1. Experimental results. - An X Ray check of our samples showed that they are single phase compounds, containing less than $1 \%$ of $\mathrm{Mo}_{2} \mathrm{~S}_{3}$. The Mössbauer experiments and the susceptibility measurements were performed on the same sample.

1) Neutron irradiation of $\operatorname{TmMo}_{6} \mathrm{~S}_{8}$ creates $\operatorname{Tm}^{170}$, which decays to $\mathrm{Yb}^{170}$. The Mössbauer emission spectrum of the $\mathrm{Yb}^{170}$ impurities created this way shows two components between $1.5 \mathrm{~K}$ and $40 \mathrm{~K}$ (Fig. 1) : - a triplet, characteristic of a pure quadrupole 


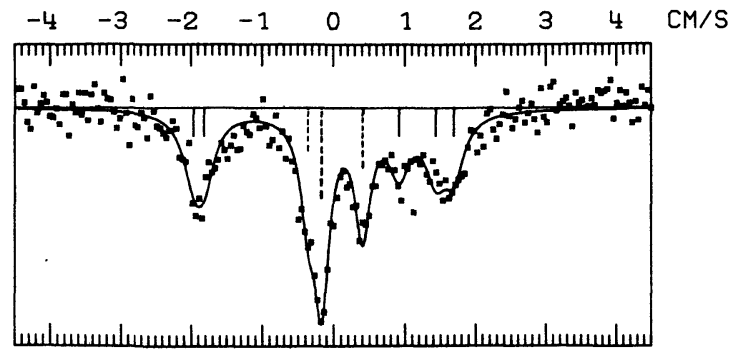

Fig. 1. - Emission Mössbauer spectrum of $\mathrm{Yb}^{170}$ in $\mathrm{TmMo}_{6} \mathrm{~S}_{8}$ at $1.5 \mathrm{~K}$ and fitted curve. (Dashed vertical lines: $\mathrm{Yb}^{2+}$ component.)

hyperfine interaction with axial symmetry $(\eta<0.2)$, corresponding to :

$\alpha=\frac{3 e Q V_{z z}}{4 I(2 I-1)}=+1.78 \mathrm{~mm} \cdot \mathrm{s}^{-1}$

$$
\text { (for } \mathrm{Yb}^{170}:\left(1 \mathrm{~mm} \cdot \mathrm{s}^{-1}=2.8 \times 10^{-6} \mathrm{eV}\right) \text {. }
$$

This triplet, which we attribute to $\mathrm{Yb}^{2+}$ ions (see the discussion below), shows a strong anomaly of the relative line intensities : $0.81: 2: 0.91$ instead of $1: 2: 2$. In our case, this anomaly cannot be due to sample thickness effects nor to inhomogeneous line broadenings. Calculations show that the observed intensities are very well accounted for by an anisotropy of the atomic vibrations that is by the GoldanskiKaryagin effect, which is observed here for the first time with the $\mathrm{Yb}^{170}$ isotope. The anisotropy cons$\operatorname{tant} a=K^{2}\left[\left\langle z^{2}\right\rangle-\left\langle x^{2}\right\rangle\right]$, where $\left\langle z^{2}\right\rangle$ and $\left\langle x^{2}\right\rangle$ are respectively the quadratic mean vibrations of $\mathrm{Yb}$ atoms parallel and perpendicular to the principal axis of the electric field gradient (EFG), is found to be $: a \simeq-3.2$ at low temperature.

This $\mathrm{Yb}^{2+}$ component shows no variation between $1.5 \mathrm{~K}$ and $40 \mathrm{~K}$.

- a spectrum, attributed to $\mathrm{Yb}^{3+}$, with an axial magnetic and quadrupole hyperfine interaction :

$$
H_{\mathrm{hf}}=A_{z} I_{z} S_{z}+\frac{A_{\perp}}{2}\left(I^{-} S^{+}+I^{+} S^{-}\right)+\alpha\left(I_{z}^{2}-2\right),
$$

in presence of slow relaxation of the $\mathrm{Yb}^{3+}$ moment within the ground Kramers doublet $\left(S=\frac{1}{2}\right.$ : effective spin of the doublet; $I:$ nuclear spin). The spectrum obtained at $1.5 \mathrm{~K}$ allows the magnetic $\left(A_{z}\right.$ and $\left.A_{\perp}\right)$ and quadrupole $(\alpha)$ hyperfine constants to be obtained. The fitted values are :

and

$$
A_{z}=9.05 \mathrm{~mm} \cdot \mathrm{s}^{-1}, \quad A_{\perp}=14.20 \mathrm{~mm} \cdot \mathrm{s}^{-1}
$$

$$
\alpha=-0.5 \mathrm{~mm} \cdot \mathrm{s}^{-1} .
$$

At higher temperature ( $T>20 \mathrm{~K})$, speeding up of relaxation produces broadening of the lines of the spectrum.

These two components have nearly equal relative intensities between $1.5 \mathrm{~K}$ and $40 \mathrm{~K}$.
2) The Mössbauer absorption spectrum of $\mathrm{Yb}^{170}$ in $\mathrm{YbMo}_{6} \mathrm{~S}_{8}$ also consists of two components between $60 \mathrm{mK}$ and $40 \mathrm{~K}$ (Fig. 2) :

- a $\mathrm{Yb}^{2+}$ triplet, presenting nearly the same features as that observed in $\mathrm{TmMo}_{6} \mathrm{~S}_{8}$ $\left(\alpha \simeq 1.85 \mathrm{~mm} \cdot \mathrm{s}^{-1} ; a \simeq-2\right)$, and showing no variation between $60 \mathrm{mK}$ and $40 \mathrm{~K}$;

- a spectrum attributed to $\mathrm{Yb}^{3+}$ in the presence of an effective field between $60 \mathrm{mK}$ and $2.75 \mathrm{~K}$ (Fig. 2a) according to the hamiltonian :

$$
H_{\mathrm{hf}}=-g_{\mathrm{n}} \mu_{\mathrm{n}} \mathbf{I} \cdot \mathbf{H}_{\mathrm{eff}}(T)+\alpha\left(I_{z}^{2}-2\right)
$$

$\left[g_{\mathrm{n}} \mu_{\mathrm{n}} I:\right.$ nuclear moment of $\left.\mathrm{Yb}^{170}\right]$.

Above $2.75 \mathrm{~K}$ (Fig. 2b) this component transforms into a pure quadrupole spectrum. Fitting the spectra below and above $2.75 \mathrm{~K}$ gives the following values :

$$
\alpha \simeq-1 \mathrm{~mm} \cdot \mathrm{s}^{-1}, \quad \mathbf{H}_{\mathrm{eff}}(0)=1770 \mathrm{kG} .
$$

$\mathbf{H}_{\text {eff }}$ is found to be perpendicular to the principal axis of the EFG tensor, that is to the ternary $\mathbf{c}$ axis.
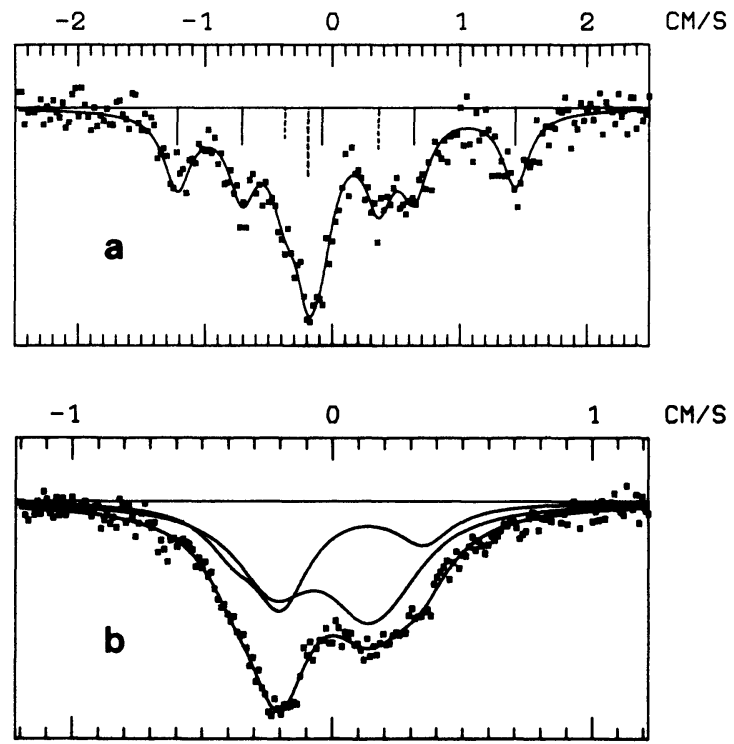

Fig. 2. - Absorption Mössbauer spectra of $\mathrm{Yb}^{170}$ in $\mathrm{YbMo}_{6} \mathrm{~S}_{8}$ and fitted curves at $60 \mathrm{mK}(a)$ and at $4.2 \mathrm{~K}(b)$. (Dashed vertical lines : $\mathrm{Yb}^{2+}$ component.)

The $\mathrm{Yb}^{2+}$ and $\mathrm{Yb}^{3+}$ components have intensities roughly $40 \%-60 \%$ in the $\mathrm{YbMo}_{6} \mathrm{~S}_{8}$ spectra. As the Mössbauer recoil-free fraction is probably weaker for the ion $\mathrm{Yb}^{2+}$ which shows a large vibrational anisotropy, the real $\mathrm{Yb}^{2+}$ ionic proportion is likely to exceed $40 \%$ in the sample.

3) Magnetic susceptibility measurements between $4.2 \mathrm{~K}$ and $40 \mathrm{~K}$ show that $1 / \chi(T)$ follows a CurieWeiss law with a slope corresponding to an effective moment per $\mathrm{Yb}$ atom :

$\mu_{\text {eff }}=2.03 \mu_{\mathrm{B}} /$ at. $\mathrm{Yb}$, in good agreement with measurements by Alekseevski et al. [3].

2. Discussion and interpretation. - 1) The existence of a cation site showing an anisotropy of atomic 
vibrations with $a=K^{2}\left[\left\langle z^{2}\right\rangle-\left\langle x^{2}\right\rangle\right]<0$ has been observed by Mössbauer effect on $\mathrm{Sn}^{119}$ in $\mathrm{SnMo}_{6} \mathrm{~S}_{8}[4,5]$. Besides this, an X-Ray study with single crystals suggests the existence in the $\mathrm{RMo}_{6} \mathrm{~S}_{8}$ phases of a more or less pronounced delocalization of the cation in a plane perpendicular to the ternary $\mathbf{c}$ axis [6].

An interesting feature of $\mathrm{Yb}^{170}$ Mössbauer spectrometry is that, unlike $\mathrm{Sn}^{119}$ spectrometry, it offers the possibility of measuring the asymmetry parameter $\eta$ of a pure quadrupole spectrum. The finding of a vanishing $\eta$ for the $\mathrm{Yb}^{2+}$ ions suggests that the EFG axis $O z$ (which is also the direction of the vibrational anisotropy) is certainly parallel to the c axis. This result is not compatible with the presence of a static delocalization of the $\mathrm{Yb}^{2+}$ ions, which would destroy the local trigonal symmetry; a dynamical delocalization preserving this symmetry is also very unlikely to occur at such low temperatures.

Another important result is the diamagnetic character of the $\mathrm{Yb}$ atoms presenting such a vibrational anisotropy. This statement is derived from the absence of any effective field on the nucleus for this kind of ions in $\mathrm{YbMo}_{6} \mathrm{~S}_{8}$ below $T_{\mathrm{N}}$, as well as from the absence of any slow relaxation magnetic hyperfine interaction at low temperature for these ions diluted in $\mathrm{Tm}_{\mathrm{Mo}} \mathrm{S}_{8}$. This diamagnetic character allows the assignation of $\mathrm{Yb}^{2+}$ to these ions.

The abnormally high value of the quadrupole constant $(\alpha \simeq 1.80 \mathrm{~mm} / \mathrm{s})$ with respect to values usually found for $\mathrm{Yb}^{2+}[8](\alpha \simeq 0.5 \mathrm{~mm} / \mathrm{s})$ might be related to the trigonal deformation of the surroundings which is also responsible for the observed vibrational anisotropy.

2) The slow relaxation Mössbauer spectrum of $\mathrm{Yb}^{3+}$ ions in $\mathrm{TmMo}_{6} \mathrm{~S}_{8}$ is not very different from the classical pattern obtained in a cubic site for a $\Gamma_{7^{-}}$ like ground Kramers doublet [7]. The $g$-tensor deduced from the measurement of the magnetic hyperfine constants is : $g_{z}=2.32 \pm 0.20$ and $g_{\perp}=3.64 \pm 0.08$ and the measured quadrupole constant is :

$$
\alpha=-0.5 \pm 0.5 \mathrm{~mm} \cdot \mathrm{s}^{-1} \text {. }
$$

These values allow the assignment of the following approximate wave function to the ground doublet of $\mathrm{Yb}^{3+}$ in $\mathrm{TmMo}_{6} \mathrm{~S}_{8}(\mathrm{Oz}:$ trigonal local axis $/ / \mathrm{c})$ :

$$
\begin{aligned}
|\psi\rangle=-0.566\left|J_{z}=\frac{7}{2}\right\rangle \pm & 0.733\left|J_{z}=\frac{1}{2}\right\rangle+ \\
& +0.376\left|J_{z}=-\frac{5}{2}\right\rangle,
\end{aligned}
$$

which compares with the $\Gamma_{7}$ wave-function :

$$
\begin{aligned}
|\psi\rangle_{\Gamma_{7}}=-0.623\left|\frac{7}{2}\right\rangle \pm 0.745\left|\frac{1}{2}\right\rangle & + \\
& +0.235\left|-\frac{5}{2}\right\rangle .
\end{aligned}
$$

3) $\mathrm{The} \mathrm{Yb}^{3+}$ spectra in $\mathrm{YbMo}_{6} \mathrm{~S}_{8}$ confirm the existence of a magnetic ordering of the electronic moments below $T_{\mathrm{N}}=2.75 \mathrm{~K}$, in the superconducting phase, in agreement with the measurements of Alek- seevski et al. [3]. Moreover, they show that the moments are perpendicular to the ternary $\mathbf{c}$ axis, and that the value of the saturation moment, derived from the value of $H_{\text {eff }}(0)$, is : $\mu_{\text {sat }}=1.70 \mu_{\mathrm{B}}$, which indicates a strong reduction relatively to the free ion value. It should be noted that other $\mathrm{REMo}_{6} \mathrm{~S}_{8}$ compounds $(\mathrm{RE}=\mathrm{Gd}, \mathrm{Tb}, \mathrm{Dy}, \mathrm{Er})$ show antiferromagnetic ordering at low temperature with the Rare Earth moments parallel to the ternary c axis [9-13].

The ground doublet of $\mathrm{Yb}^{3+}$ in $\mathrm{YbMo}_{6} \mathrm{~S}_{8}$ must not be very different from that of $\mathrm{Yb}^{3+}$ in $\mathrm{TmMo}_{6} \mathrm{~S}_{8}$ : the observed $g$-tensor anisotropy in $\mathrm{TmMo}_{6} \mathrm{~S}_{8}$ matches with an easy direction of magnetization perpendicular to the $\mathbf{c}$ axis and the value $g_{\perp}=3.64$ is compatible with a saturation moment of $1.70 \mu_{\mathrm{B}}$ in $\mathrm{YbMo}_{6} \mathrm{~S}_{8}$.

Above the magnetic transition temperature $T_{\mathrm{N}}$, the quadrupole $\mathrm{Yb}^{3+}$ spectrum in $\mathrm{YbMo}_{6} \mathrm{~S}_{8}$ is reasonably accounted for without any vibrational anisotropy $(a=0)$, in contrast with the $\mathrm{Yb}^{2+}$ site results.

4) The value of the effective magnetic moment measured by susceptibility $\left(\mu_{\text {eff }}=2.03 \mu_{\mathrm{B}} / \mathrm{at}\right.$. Y Y $)$ in $\mathrm{YbMo}_{6} \mathrm{~S}_{8}$ is in good agreement with the value calculated using the g-tensor of $\mathrm{Yb}^{3+}\left(S=\frac{1}{2}\right)$ in $\mathrm{TmMo}_{6} \mathrm{~S}_{8}$, when assuming equipopulation of $\mathrm{Yb}^{2+}$ and $\mathrm{Yb}^{3+}$ ions :

$$
\begin{aligned}
\mu_{\text {eff }}=\sqrt{0.5} \frac{g_{z}+2 g_{\perp}}{3} \times \sqrt{S(S+1)} \mu_{\mathrm{B}} \Rightarrow \\
\quad \Rightarrow \mu_{\text {eff }}=1.96 \mu_{\mathrm{B}} / \text { at. Yb. }
\end{aligned}
$$

$\mathrm{Yb}^{2+}$ and $\mathrm{Yb}^{3+}$ equipopulation is not incompatible with the Mössbauer spectra which show that the proportion of the $\mathrm{Yb}^{2+}$ ions is larger than $40 \%$.

5) Preliminary results of a Mössbauer study of $\mathrm{TmMo}_{6} \mathrm{~S}_{8}$ with the isotope $\mathrm{Tm}^{169}$ show a unique quadrupole doublet $\left(\Delta E=3.2 \mathrm{~cm} . \mathrm{s}^{-1}\right)$ at low temperatures.

3. Conclusion. - Mössbauer effect study with $\mathrm{Yb}^{170}$ and powder magnetic susceptibility measurements on $\mathrm{YbMo}_{6} \mathrm{~S}_{8}$ revealed the presence of two types of Ytterbium atoms, with nearly equal proportions. First, diamagnetic $\mathrm{Yb}^{2+}$ ions, submitted to a very strong axial EFG, which evidence a strong anisotropy of the Mössbauer recoil free fraction and which vibrate preferentially within a plane perpendicular to the EFG axis (which is probably the ternary c axis). Second, magnetic $\mathrm{Yb}^{3+}$ ions, submitted to a predominant cubic crystal field with a small trigonal component, and whose ground electronic doublet is close to a $\Gamma_{7}$ doublet; the vibrations in this site are quite isotropic. Their magnetic moments are ordered perpendicularly to the ternary c axis below $T_{\mathrm{N}}=2.75 \mathrm{~K}$ in the superconducting state. Neutron diffraction experiments are in preparation in order to determine the nature of the magnetic ordering in this compound.

The presence of $\mathrm{Yb}^{2+}$ ions probably accounts for the high superconducting transition temperature of 
$\mathrm{YbMo}_{6} \mathrm{~S}_{8}$ with respect to other $\mathrm{REMo}_{6} \mathrm{~S}_{8}$ compounds [2].

In $\mathrm{TmMo}_{6} \mathrm{~S}_{8}$, the Mössbauer study with $\mathrm{Tm}^{169}$ did not show the presence of two different types of ions or sites. On the contrary, the study of dilute $\mathrm{Yb}^{170}$ impurities created by radioactive decay of $\mathrm{Tm}^{170}$ after neutron irradiation of $\mathrm{TmMo}_{6} \mathrm{~S}_{8}$ reveals again the presence of $\mathrm{Yb}^{2+}$ and $\mathrm{Yb}^{3+}$ ions with comparable proportions, and whose single-ion properties are similar to those observed in $\mathrm{YbMo}_{6} \mathrm{~S}_{8}$.

In both samples, crossing the superconducting transition temperature does not involve any change, in first approximation, in Mössbauer spectra, confirming the weak interaction existing in $\mathrm{REMo}_{6} \mathrm{X}_{8}$ superconductors between $d$ superconducting electrons and $4 \mathrm{f}$ electrons of the Rare Earth.

\section{References}

[1] Fischer, Ø., Appl. Phys. 16 (1978) 1.

[2] Fischer, $\emptyset$., Treyvaud, A., Chevrel, R. and Sergent, M., Solid State Commun. 17 (1975) 721.

[3] Alekseevski, N. E., Wolf, G., Bohmhammel, K., Dobrovolski, N. M. and Hohlfeld, C., Phys. Status Solidi (a) 51 (1979) 399.

[4] Kimball, C. W., Weber, L., van Landuyt, G., Fradin, F. Y., Dunlap, B. D. and Shenoy, G. K., Phys. Rev. Lett. 36 (1976) 412.

[5] Bolz, J., Hauck, J. and Pobell, F., Z. Phys. B 25 (1976) 351.

[6] Yvon, K., Solid State Commun. 25 (1978) 327.

[7] Gonzalez-Jimenez, F., Imbert, P., Solid State Commun. 11 (1972) 861 ;
GonZalez-Jimenez, F., Imbert, P., Int. Conf. Magn. Moscow (1973) Proceedings V, 73.

[8] Bonville, P., Imbert, P., Jehanno, G., Gonzalez-Jimenez, F., J. Phys. Chem. of Solids 39 (1978) 1273.

[9] Ishikawa, M. and Fischer, Ø., Solid State Commun. 24 (1977) 747.

[10] Lynn, J. W., Moncton, D. E., ShiRane, G., Thomlinson, W., ECKert, J., Shelton, R. N., J. Appl. Phys. 49 (1978) 1389.

[11] Ishikawa, M., Fischer, $\emptyset$. and Muller, J., J. Physique Colloq. 39 (1978) C6-1379.

[12] Thomlinson, W., Shirane, G., Moncton, D. E., Ishikawa, M., Fischer, Ø., J. Appl. Phys. 50 (1979) 1981.

[13] Moncton, D. E., J. Appl. Phys. 50 (1979) 1880. 